\title{
RELATIONSHIPS BETWEEN PHYSICAL FITNESS COMPONENTS AMONG SLOVAK HIGH SCHOOL STUDENTS
}

\author{
MILAN TUREK, PAVEL RUZBARSKY, MAREK KOKINDA, \\ VIERA SMERECKA, MARIO JANCOSEK, ROBERT KANDRAC \\ University of Prešov, Faculty of Sports, Department of Sport Kinanthropology \\ Mailing address: Robert Kandrac, Faculty of Sports, \\ Department of Sport Kinanthropology, $1317^{\text {th }}$ Novembra Street, 08116 Prešov, \\ tel.: + 42151 7470523, fax: + 42151 7734751, e-mail: robert.kandrac@unipo.sk
}

\begin{abstract}
Introduction. The purpose of the study was to assess physical fitness based on using FITNESSGRAM test battery in Slovak high school students. Material and methods. The reference sample consisted of 1,016 high school students from schools located in the Prešov self-governing region. Students were tested for physical fitness components using selected Fitnessgram test items. In addition, students performed 20-meter endurance shuttle run to determine their level of cardiorespiratory fitness and 10-second jumping test on a jumping ergometer to determine their lower-body explosive power. Results. Results of one-way ANOVA showed significant differences for curl-up test $(\mathrm{p}=.012)$ between 15-year-old boys and 18-year-old boys. There were no differences between boys living in rural areas and their age-matched counterparts living in urban areas. Contrary to boys, girls from rural areas had higher level of abdominal strength $(p=.046 ; d=.19)$. In the 20-meter endurance shuttle run, boys averaged 448.87 meters more than girls. Conclusions. This study enables to create norm-referenced standards, which through their content will to a great extent indicate the measures of physical fitness.
\end{abstract}

Key words: fitnessgram, motor development, physical activity, adolescence

\section{Introduction}

Physical fitness consisting of cardiorespiratory fitness, muscular fitness, speed and agility in childhood and adolescence is a powerful marker of current and future health status and is associated with a favorable metabolic profile $[1,2,3]$. Those with higher physical fitness levels or with greater weekly physical activity or energy expenditure have been shown to have fewer health risks [4]. Moderate and vigorous levels of physical activity stimulate functional adaptation of all tissues and organs in the body, thereby also making them less vulnerable to lifestylerelated degenerative and chronic diseases [5]. Improvements in cardiorespiratory fitness have positive effects on depression, anxiety, mood status and self-esteem, and seem also to be associated with a higher academic performance. Aerobic fitness among almost two thirds of European adolescents is associated with low risk of cardiovascular disease. The assessment of physical fitness levels in European adolescents showed that higher aerobic fitness was associated with more favorable levels of cardiovascular disease markers such as cholesterol, triacylglycerol, homocysteine and insulin resistance [3].

Health-related fitness has been studied by a variety of authors from different perspectives [4, 6, 7, 8, 9]. Authors of the studies most often used Fitnessgram test battery to determine the level of health-related fitness of children and adolescents [10].

However, this test battery has scarcely been used in central European countries, where different test batteries such as EUROFIT [11] and UNIFITTEST [12, 13] have been administered. There is information lacking on the health-related fitness status of Slovak adolescents as the two most recent studies dealing with physical fitness of Slovak adolescents were con- ducted almost twenty years ago [14, 15]. The Fitnessgram test battery has not been used to measure health-related fitness of Slovak youth so far. Partial information has been provided by Suchomel who measured fitness level of Czech children using Fitnessgram [16, 17]. The present study provides information about health-related fitness data for adolescents attending high schools in Slovakia.

\section{Material and methods}

Students attending high schools located in the eastern Slovakia region performed FITNESSGRAM test items in order to determine their level of physical fitness. The reference sample consisted of 1,016 students attending 14 high schools located in the Prešov self-governing region. Descriptive characteristics of the sample according to chronological age are presented in table 1.

Physical fitness testing was conducted after obtaining written informed consents with active participation of students in fitness testing sessions. Physical fitness of students was assessed using FITNESSGRAM test battery [10]. Students performed particular tests to determine their level of abdominal strength and endurance (curl-ups), upper body strength and endurance (90-degree push-ups), hamstring muscles and lower back flexibility (back saver sit and reach test), and upper arm and shoulder girdle flexibility (shoulder stretch).

Fitnessgram test battery was complemented by 20-meter endurance shuttle run [18] and a 10-second jumping test performed on a jumping ergometer described by Zemková and Dzurenková [19]. The test consisted of repeated two-legged vertical jumps performed with maximum effort. 
Table 1. Descriptive characteristics of the sample

\begin{tabular}{|c|c|c|c|c|c|c|c|c|c|c|c|c|c|c|c|c|c|c|c|c|c|c|c|c|}
\hline & \multicolumn{8}{|c|}{ Body height (cm) } & \multicolumn{8}{|c|}{ Body mass (kg) } & \multicolumn{8}{|c|}{ BMI } \\
\hline Age & \multicolumn{2}{|c|}{15} & \multicolumn{2}{|c|}{16} & \multicolumn{2}{|c|}{17} & \multicolumn{2}{|c|}{$17+$} & \multicolumn{2}{|c|}{15} & \multicolumn{2}{|c|}{16} & \multicolumn{2}{|c|}{17} & \multicolumn{2}{|c|}{$17+$} & \multicolumn{2}{|c|}{15} & \multicolumn{2}{|c|}{16} & \multicolumn{2}{|c|}{17} & \multicolumn{2}{|c|}{$17+$} \\
\hline$n$ & \multicolumn{2}{|c|}{89} & \multicolumn{2}{|c|}{149} & \multicolumn{2}{|c|}{95} & \multicolumn{2}{|c|}{134} & \multicolumn{2}{|c|}{89} & \multicolumn{2}{|c|}{149} & \multicolumn{2}{|c|}{95} & \multicolumn{2}{|c|}{134} & \multicolumn{2}{|c|}{89} & \multicolumn{2}{|c|}{149} & \multicolumn{2}{|c|}{95} & \multicolumn{2}{|c|}{134} \\
\hline \multirow{2}{*}{$\begin{array}{c}\text { Boys } \\
(n=467)\end{array}$} & M & SD & M & SD & M & SD & M & SD & M & SD & M & SD & M & SD & M & SD & M & SD & M & SD & M & SD & M & SD \\
\hline & 175.52 & 6.65 & 175.91 & 10.4 & 177.05 & 6.47 & 177.47 & 6.8 & 64.75 & 12.64 & 66.71 & 11.55 & 67.86 & 11.98 & 70.42 & 12.22 & 21.16 & 3.5 & 22.25 & 7.5 & 21.89 & 3.31 & 22.49 & 3.41 \\
\hline$n$ & \multicolumn{2}{|c|}{118} & \multicolumn{2}{|c|}{149} & \multicolumn{2}{|c|}{116} & \multicolumn{2}{|c|}{166} & \multicolumn{2}{|c|}{118} & 1 & 49 & & 16 & 16 & 6 & 118 & 8 & 145 & & 11 & & 16 & \\
\hline Girls & M & SD & M & SD & M & SD & $M$ & SD & M & SD & M & SD & M & SD & M & SD & M & SD & M & SD & M & SD & M & SD \\
\hline & 164.46 & 5.64 & 164.24 & 5.6 & 165.44 & 5.86 & 165.2 & 6.04 & 57.42 & 9.7 & 58.04 & 11.15 & 60.38 & 11.27 & 59.42 & 10.65 & 20.94 & 2.89 & 21.16 & 3.53 & 21.71 & 3.53 & 21.63 & 3.45 \\
\hline
\end{tabular}

Note: $\mathrm{M}=$ arithmetic means; $\mathrm{SD}=$ standard deviations; $\mathrm{n}$ = sample size.

Participant's legal representative (in the case when a child was younger than 18 years of age) or participants (in the case when a child was older than 18 years of age) received a verbal description of the study procedures before testing and completed a written informed consent that was approved by the Ethics commission of University of Presov in Presov. Measurements were taken according to the ethical standards of the Declaration of Helsinki [20].

Differences among group means were determined using one-way ANOVA test. Relations between age groups of boys and girls were analyzed via post-hoc Scheffe test. The effect of place of residence of physical fitness levels was determined using t-test for independent samples. The values of Paerson's correlation coefficients rp [21] were used to determine the effect size. The magnitude of relationships was assessed on the basis of absolute values of coefficient rp [22].

Practical significance was based on Cohen's effect size [23]. The values of Cohen's d were calculated using formula for two compared variables [21]. The assessment of percentile numbers enables to assign all participants according to their physical fitness levels to groups with below average and above average fitness levels in samples ranging from $25 \%$ to $75 \%$. At the same time, this provides information about the proportion of participants with standard health status.

The research question is: What is the information value of the selected Fitnessgram test items when assessing physical fitness of Slovak high school students?

\section{Results}

Particular test scores were converted to C-scores and linear correlation was used to determine the magnitude of relationship among variables within the motor domain. The correlations are presented in tables 2 and 3.

For boys, correlations revealed that back saver sit and reach test and shoulder stretch assess the same fitness component. The parameter of jump height indicates lower body explosive power more precisely compared to power in the concentric phase of take-off, which appears to be not sensitive enough to other test items. This might reduce the quality of the test battery. This test battery is used to assess strength endurance, endurance, flexibility and joint flexibility. Curl-up test and 20-meter endurance shuttle run, which did not correlate significantly, appear to be relatively specific indicators of particular motor domains. The analysis partially indicates test redundancy, which may to certain extent negatively affect its information value as we are unable to determine which of the tests best indicates the parameter measured.
Table 2. Values of correlation coefficients (boys $n=467$ )

\begin{tabular}{|l|c|c|c|c|c|c|c|c|}
\hline VARIABLES: & 1. & 2. & 3. & 4. & 5. & 6. & 7. & $\mathbf{8 .}$ \\
\hline 1. Curl Up & - & & & & & & & \\
\hline 2. Push-Up $90^{\circ}$ & & - & & & & & & \\
\hline 3. Back-Saver Sit and Reach (L) & & $0.22^{*}$ & - & & & & & \\
\hline 4. Back-Saver Sit and Reach (R) & & & $0.95^{* *}$ & - & & & & \\
\hline 5. Shoulder stretch & & & $0.22^{*}$ & $0.24^{*}$ & - & & & \\
\hline 6. Jumping ergometer (P) & & & & & & - & & \\
\hline 7. Jumping ergometer (h) & & $0.19^{*}$ & $0.23^{*}$ & $0.21^{*}$ & & $0.26^{* *}$ & - & \\
\hline 8. 20-meter endurance shuttle run & & & & & & & & - \\
\hline \\
Level of significance: $\mathrm{r}_{0.19^{\prime}} \mathrm{r}_{0.25^{*}}$
\end{tabular}

Note: $P=$ power in the concentric phase of take-off per $k g$ body mass; $h=$ jump height; $n=$ sample size.

Table 3. Values of correlation coefficients (girls $n=549$ )

\begin{tabular}{|l|c|c|c|c|c|c|c|c|}
\hline VARIABLES: & 1. & 2. & 3. & 4. & 5. & 6. & 7. & $\mathbf{8 .}$ \\
\hline 1. Curl Up & - & & & & & & & \\
\hline 2. Push-Up $90^{\circ}$ & & - & & & & & & \\
\hline 3. Back-Saver Sit and Reach (L) & & & - & & & & & \\
\hline 4. Back-Saver Sit and Reach (R) & & & $0.95^{* *}$ & - & & & & \\
\hline 5. Shoulder stretch & & $0.66^{* *}$ & & & - & & & \\
\hline 6. Jumping ergometer (P) & $-0.26^{* *}$ & & & & & - & & \\
\hline 7. Jumping ergometer (h) & & & & & & & - & \\
\hline 8. 20-meter endurance shuttle run & & & & & & & & - \\
\hline
\end{tabular}

Level of significance: $r_{0.19} ; r_{0.25}$.

Note: $P=$ power in the concentric phase of take-off per kg body mass; $h=$ jump height; $n=$ sample size.

Particular correlates for the sample of girls have shown that the indicators meet the assessment criteria of correlation relationships similarly to the sample of boys. A paradoxically significant correlation was found between curl-ups and power in the concentric phase of take-off. The sizes of both samples enable to postulate critical significance levels, which increases applicability and information value of administered tests. Descriptive characteristics for particular tests are presented in table 4.

Upper arm and shoulder girdle flexibility were assessed on a pass/fail binary basis. Of all participants, 51 boys (10.71\%) failed to complete the shoulder stretch test. Compared to boys, 25 girls $(4.55 \%)$ did not complete the shoulder stretch test. One-way ANOVA showed statistically significant differences for curl-up test $(\mathrm{p}=.037)$ between 15 -year-old boys and 18-year-old boys.

For boys, the place of residence did not have statistically significant effect on physical fitness levels. However, girls liv- 
ing in rural areas had higher level of abdominal strength and endurance ( $p=.046 ; d=.19)$ compared to their counterparts living in urban areas. Identical findings were found for back saver sit and reach test $(\mathrm{p}=.004 ; \mathrm{p}=.008)(\mathrm{d}=.28 ; \mathrm{d}=.26)$, respectively. Higher degree of hamstring and lower back flexibility was found for girls living in rural areas $(\mathrm{d}=.28$; $\mathrm{d}=.26)$.

Table 4. Arithmetic means and standard deviations of boys and girls

\begin{tabular}{|l|c|c|c|c|}
\hline \multirow{2}{*}{ VARIABLES: } & \multicolumn{2}{|c|}{ Boys $(\boldsymbol{n}=\mathbf{4 7 6})$} & \multicolumn{2}{c|}{ Girls $(\boldsymbol{n}=\mathbf{5 4 9})$} \\
\cline { 2 - 5 } & $\mathbf{M}$ & SD & M & SD \\
\hline 1. Curl Up (number) & 33.53 & 23.35 & 36.75 & 13.31 \\
\hline 2. Push-Up $90^{\circ}$ (number) & 32.93 & 14.69 & 12.1 & 8.84 \\
\hline 3. Back-Saver Sit and Reach $(\mathrm{L} / \mathrm{cm})$ & 2.13 & 6.56 & 6.42 & 6.75 \\
\hline 4. Back-Saver Sit and Reach $(\mathrm{R} / \mathrm{cm})$ & 2.32 & 6.14 & 7.34 & 6.42 \\
\hline 5. Shoulder stretch $(\boldsymbol{P} / \mathrm{W} / \mathrm{kg})$ & 37.74 & 8.13 & 29.11 & 5.85 \\
\hline 6. Jumping ergometer $(\mathrm{h} / \mathrm{cm})$ & 28.27 & 5.75 & 20.68 & 3.89 \\
\hline 7. Jumping ergometer $(\mathrm{m})$ & 1088.51 & 449.62 & 639.64 & 293.09 \\
\hline
\end{tabular}

Note: $\mathrm{M}$ = arithmetic means; $\mathrm{SD}=$ standard deviations; $\mathrm{n}=$ sample size.

The Cohen d values [21] were used to compare groups of boys and girls in all tests. On average, girls performed 3.22 curl-ups more than boys. This difference was characterized by small effect size $(d=.17)$. However, boys completed 20.83 more push-ups than girls $(\mathrm{d}=1.7)$.

Table 5. Percentile intervals for Fitnessgram test items (boys $n=467)$

\begin{tabular}{|c|c|c|c|}
\hline \multirow{3}{*}{ Age } & \multicolumn{3}{|c|}{ Percentile interval } \\
\hline & $25 \%$ & $50 \%$ & $75 \%$ \\
\hline & \multicolumn{3}{|c|}{ Curl Up } \\
\hline 15 & 26.50 & 41.00 & 75.00 \\
\hline 16 & 20.00 & 33.00 & 55.00 \\
\hline 17 & 18.00 & 30.00 & 49.25 \\
\hline \multirow[t]{2}{*}{$17+$} & 20.00 & 30.00 & 46.00 \\
\hline & \multicolumn{3}{|c|}{ Push-Up 90 } \\
\hline 15 & 20.00 & 31.00 & 40.00 \\
\hline 16 & 25.00 & 32.00 & 45.00 \\
\hline 17 & 27.00 & 35.00 & 46.00 \\
\hline \multirow[t]{2}{*}{$17+$} & 27.00 & 33.50 & 45.00 \\
\hline & \multicolumn{3}{|c|}{ Back-Saver Sit and Reach L } \\
\hline 15 & -4.25 & 2.00 & 8.00 \\
\hline 16 & -2.00 & 4.00 & 8.00 \\
\hline 17 & -1 & 4.5 & 8.75 \\
\hline \multirow[t]{2}{*}{$17+$} & -2.00 & 4.00 & 9.00 \\
\hline & \multicolumn{3}{|c|}{ Back-Saver Sit and Reach $\mathbf{R}$} \\
\hline 15 & -5.00 & 1.00 & 5.50 \\
\hline 16 & -2.25 & 3.50 & 8.00 \\
\hline 17 & -1.75 & 3 & 9 \\
\hline $17+$ & -2.00 & 3.00 & 9.00 \\
\hline
\end{tabular}

Note: $\mathrm{n}=$ sample size.

Hamstring flexibility for left and right leg differed more significantly for girls (see tab. 2). The difference between boys and girls was expressed by medium effect size for both left leg $(d=.64)$ and right leg $(d=.79)$. For lower body explosive pow- er, boys showed higher level of explosiveness in both power $(\mathrm{W} / \mathrm{kg}$ ) and jump height $(\mathrm{cm})$ compared to girls (tab. 2).

Mean power in the concentric phase of jump $8.63(\mathrm{~W} / \mathrm{kg})$ was lower in girls than boys $(\mathrm{d}=1.2)$. The average jump height of girls was $7.59 \mathrm{~cm}$ lower than average jump height of boys $(d=1.5)$. Cardiorespiratory fitness determined using 20-meter endurance shuttle run was higher in boys who covered 448.87 meters more compared to girls $(d=1.2)$.

Table 6. Percentile intervals for Fitnessgram test items (girls $n$ $=549$ )

\begin{tabular}{|c|c|c|c|}
\hline \multirow{3}{*}{ Age } & \multicolumn{3}{|c|}{ Percentile interval } \\
\hline & $25 \%$ & $50 \%$ & $75 \%$ \\
\hline & \multicolumn{3}{|c|}{ Curl Up } \\
\hline 15 & 15.50 & 25.00 & 37.75 \\
\hline 16 & 12.00 & 25.00 & 37.00 \\
\hline 17 & 15.00 & 26.00 & 41.00 \\
\hline \multirow[t]{2}{*}{$17+$} & 13.00 & 22.00 & 32.00 \\
\hline & \multicolumn{3}{|c|}{ Push-Up 90 } \\
\hline 15 & 2.00 & 8.00 & 13.50 \\
\hline 16 & 2.25 & 8.50 & 15.00 \\
\hline 17 & 2.00 & 6.50 & 13.00 \\
\hline \multirow[t]{2}{*}{$17+$} & 1.00 & 6.00 & 14.00 \\
\hline & \multicolumn{3}{|c|}{ Back-Saver Sit and Reach L } \\
\hline 15 & 2.00 & 7.00 & 12.00 \\
\hline 16 & 2.00 & 7.00 & 11.00 \\
\hline 17 & 2.5 & 7.00 & 12.00 \\
\hline \multirow[t]{2}{*}{$17+$} & 2.00 & 7.00 & 11.00 \\
\hline & \multicolumn{3}{|c|}{ Back-Saver Sit and Reach $\mathbf{R}$} \\
\hline 15 & 2.00 & 7.00 & 11.00 \\
\hline 16 & 2.00 & 7.00 & 11.00 \\
\hline 17 & 1.00 & 6.00 & 12.00 \\
\hline $17+$ & 2.00 & 6.00 & 11.00 \\
\hline
\end{tabular}

Note: $\mathrm{n}=$ sample size.

Tables 5 and 6 present measures of variation of distributed random variable (percentile), which indicates percentage of distribution around group average expressed by median (50\%) and placement of participants within the percentile ranges of the reference group.

Physical fitness level of high school students was estimated and assessed using a percentile scale, which enables to assign all scores according to actual physical fitness indicators and health measures to ranges above and below average ranging from $25 \%$ to $75 \%$.

The curl-up test scores for 15-, 16-, 17- and 18-year-old boys showed that 15-year-old students completed the highest number of repetitions ranging from 26.5 to 75 repetitions. The highest number of repetitions in the push-up test was completed by 17-year-old students. The number of repetitions ranged from 27 to 46 . Hamstring flexibility for both legs was quite heterogeneous for both reference samples. The highest degree of flexibility was found for 17-year-olds for both the right and left leg.

The highest number of curl-ups was performed by 17-yearold girls. The number of repetitions for the test ranged from 15 to 41 . The highest number of push-ups, ranging from 2.25 to 15 repetitions, was completed by 16 -year-old girls. Compared to boys, girls showed higher degree of hamstring flexibility especially in the 17-year-old group. 


\section{Discussion}

Our findings are not consistent with results reported by Moravec [14] who found that physical fitness level of girls and boys living in urban areas increased at a faster rate compared to those living in rural areas. This was not found for running endurance, the level of which was higher in boys living in rural areas. There were no statistical differences between girls living in rural and urban areas for running endurance. As reported by Ortega et al. [2] greater physical fitness in the boys, except for the flexibility test, and a trend towards increased physical fitness in the boys as their age increased, whereas the fitness levels in the girls were more stable across ages.

Data about physical fitness levels of high school students presented in this study should be regarded as preliminary due to the use of performance standards valid for American population, not Slovak population. At the same time, it would be appropriate to apply multivariate mathematical and statistical methods to examine and select test items the information value of which would be sufficient to determine physical fitness levels of students living in the specific region of central Europe. This especially pertains to cultural, social and economic aspects associated with quality of life.

\section{Conclusions}

Physical fitness level during childhood and adolescence is a significant measure of health risks during present and future stages of life. Health-related fitness is a combination of aerobic capacity, strength, speed, agility and flexibility, which determine the capacity for performing physical activity including activities of daily living. The effect of place of residence on physical fitness levels was statistically insignificant. Girls showed higher level of abdominal strength and hamstring and lower back flexibility. Significant differences in physical fitness tests among age groups were found between 15- and 18-yearold boys for curl-up test. Cardiorespiratory fitness level determined by multistage shuttle run was higher among boys than girls. The present study may be used to devise norm-referenced standards for the assessment of health-related fitness. These standards can to a large extent underlie implementation of strategies for health promotion and fitness enhancement.

Present study provides data on physical fitness levels of a representative sample of Slovak high school students living in the Prešov self-governing region. A research of such extent and focus was last conducted 24 years ago. The research findings are generalizable for the investigated geographical area and provide a demographic assessment. The administration of Fitnessgram test battery enables to collect physical fitness data on a global scale outside the European continent depending on social, economic, anthropologic and ethnographic indicators. Decreasing the absence of evidence and knowledge may provide more information on tendencies related to somatic and motor development of adolescents and recommend ways of eliminating potential negative effects on promotion of quality of life.

Norm-referenced standards designed for American population are specific in terms of movement culture and therefore probably lead to significant differences when compared to the central European population. This issue is associated with long-term rational work with students, which begins in the family environment and continues during their study at elementary schools. Among one of the main criteria underlying preparation of students in this stage is motivation and adoption of positive attitude towards physical activities.

As reported by Michal, Kollár, Kružliak [24], 75.36\% of boys and $69.52 \%$ of girls showed positive attitude towards physi- cal activities, respectively. Interest of students in school-based physical activities is greater in first graders than in fourth graders, where $49.28 \%$ of first graders and $36.7 \%$ of fourth graders were interested in physical activities, respectively. Thus, the innovation of thematic units is one of the possibilities of making high school students more interested in physical activities, where conditioning exercise as a thematic unit has positive educational, motivational and formative effects [25].

\section{Acknowledgments}

This study was supported by Slovak Research and Development Agency pursuant to agreement no. APVV-0768-11.

\section{Literature}

1. Ekelund U., Anderssen S.A., Froberg K., Sardinha L.B., Andersen L.B., Brage S. (2007). Independent associations of physical activity and cardiorespiratory fitness with metabolic risk factors in children: the European youth heart study. Diabetelogia 50(9), 1832-1840. DOI: 10.1007/ s00125-007-0762-5

2. Ortega F.B., Artero E.G., Ruiz J.R., Espana-Romero V., Jimenéz-Pavón D., Vicente-Rodriguez D. et al. (2011). Physical fitness levels among European adolescents: The HELENA Study. British Journal of Sports Medicine 45(1), 20-29. DOI: 10.1136/bjsm.2009.062679

3. Ortega F.B., Ruiz J.R., Castillo M.J., Sjöström M. (2008). Physical fitness in childhood and adolescence a powerful marker of health. International Journal of Obesity 32(1), 1-11. DOI: 10.1038/sj.ijo.0803774

4. Morrow J.R., Tucker J.S., Jackson A.W., Martin S.B., Greenleaf C.A., Petrie T.A. (2013). Meeting physical activity guidelines and health-related fitness in youth. American Journal of Preventive Medicine 44(5), 439-444. DOI: 10.1016/j.amepre.2013.01.008

5. Ruiz J.R., Ortega F.B., Gutierrez A., Meusel D., Sjöström M., Castillo M.J. (2006). Health-related fitness assessment in childhood and adolescence: a European approach based on the AVENA, EYHS and HELENA studies. Journal of Public Health 14(5), 269-277. DOI: 10.1007/s10389-006-0059-z

6. Liu W., Nichols R.A., Zillifro T.D. (2013). Comparison and comparability: Fitness tracking between youths with different physical activity levels. Measurement in Physical Education and Exercise Science 17(4), 295-309. DOI: 10.1080/1091367X.2013.831764

7. Moliner-Urdiales D., Ruiz J.R., Ortega F.B., Jiménez-Pavón D., Vicente-Rodriguez G., Rey-Lopéz J.P. (2010). Secular trends in health-related physical fitness in Spanish adolescents: The AVENA and HELENA studies. Journal of Science and Medicine in Sport 13(6), 584-588. DOI: 10.1016/j. jsams.2010.03.004

8. Welk G.J., Jackson A.W., Morrow J.R., Haskell W.H., Meredith M.D., Cooper K.H. (2010). The association of healthrelated fitness with indicators of academic performance in Texas Schools. Research Quarterly for Exercise and Sport 81, 16-23. DOI: 10.1080/02701367.2010.10599690

9. Welk G.J., Meredith M.D., Ihmels M., Seeger C. (2010). Distribution of health-related physical fitness in Texas Youth: A demographic and geographic analysis. Research Quarterly for Exercise and Sport 81, 6-15. DOI: 10.1080/02701367.2010.10599689

10. Meredith M.D., Welk G.J. (2010). FITNESSGRAM \& ACTIVITYGRAM Test Administration Manual. Champaign, Illinois: Human Kinetics.

11. Oja P., Tuxworth B. (1997). Eurofit for adults: Assessment of health-related fitness. Praha: Karolinum. [in Czech] 
12. Chytráčková J. (Ed.). (2002). UNIFITTTEST (6-60). Manual for manual and computer assessment of basic motor fitness and selected characteristics of body build of youth and adults in the Czech Republic. Praha: FTVS UK. [in Czech]

13. Měkota K., Kovář R. (1995). UNIFITTEST (6-60): tests and norms for motor performance and physical fitness in youth and in adult age. Olomouc: Univerzita Palackého.

14. Moravec R. (1990). Somatic, functional and motor fitness of 7-18-year old youth in CSFR. Bratislava: MŠMŠ SR. [in Slovak]

15. Moravec R., Kampmiller T., Sedlacek J. (1996). Eurofit. Somatic development and motor fitness in school population in Slovakia. Bratislava: SVSTVŠ. [in Slovak]

16. Suchomel A. (2004). Somatic characteristic of school-aged children with different levels of motor fitness. Liberec: Technická univerzita v Liberci. [in Czech]

17. Suchomel A. (2006). Physically unfit school-aged children (motor assessment, primary factors of incidence, conditioning programs). Liberec: Technická univerzita v Liberci. [in Czech]

18. Léger L.A., Mercier D., Gadoury C., Lambert J. (1988). The multistage 20 metre shuttle run test for aerobic fitness. Journal of Sports Sciences 6(2), 93-101. DOI: 10.1080/02640418808729800

19. Zemková E., Dzurenková D. (2006). The use of jumping ergometer for the purpose of talent selection and assessment of lower-body jumping abilities. Telesná výchova a šport 16(4), 24-28. [in Slovak]

20. Harriss D.J., Atkinson G. (2011). Update-ethical standards in sport and exercise science research. International Journal of Sports Medicine 32(11), 819-821. DOI: 10.1055/s0033-1358756

21. Sigmundová D., Sigmund E. (2010). Statistical and practical significance and the use of the coefficient „effect size“ when evaluating physical activity data. Tělesná kultura 35(1), 55-72. DOI: 10.5507/tk.2012.004 [in Czech]

22. Hendl J. (2004). Overview of statistical data processing methods. Praha: Portál. [in Czech]

23. Cohen J. (1988). Statistical power analysis for the behavioral sciences (2nd ed.). Hillsdale: Lawrence Erlbaum Associates.

24. Michal J., Kollár R., Kružliak M. (2010). Opinions and attitudes of high school students to physical activities, physical and sports education. In M. Majherova (ed.), Pohybová aktivita v živote človeka - Pohyb detí (pp. 122-129). Prešov: Prešovská univerzita. [in Slovak]

25. Šmela P., Peráčková J. (2012). Evaluation of the thematic unit fitness training at high school. In A. Cepkova (ed.) Od výskumu k praxi v športe (pp. 275-280). Bratislava. STU Bratislava. [in Slovak].

Submitted: April 21, 2015

Accepted: November 30, 2015 